
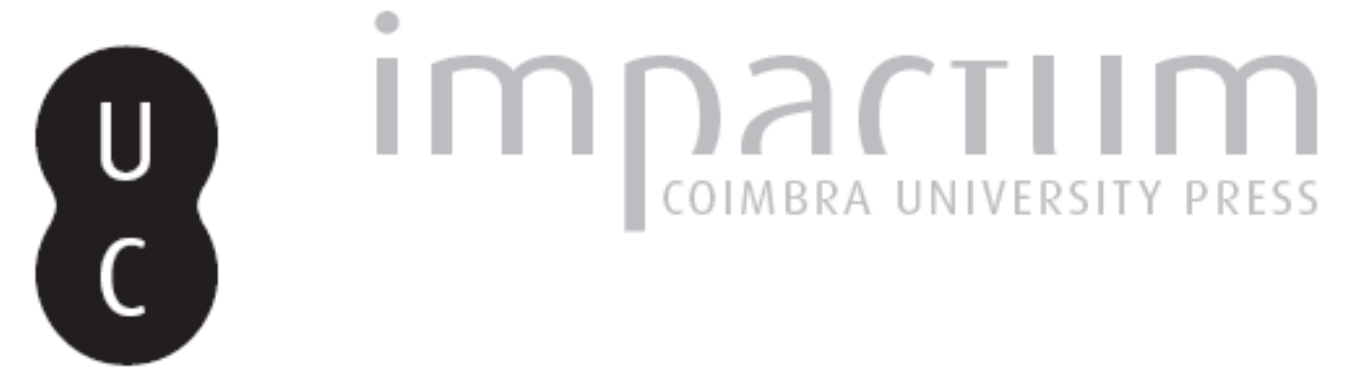

\title{
Directiva inundações: novas perspectivas
}

Autor(es): $\quad$ Nobre, Márcio Albuquerque

\section{Publicado por: CEDOUA}

\section{URL} persistente:

URI:http://hdl.handle.net/10316.2/8827

DOI:

http://dx.doi.org/10.14195/2182-2387_21_6

Accessed : $\quad$ 26-Apr-2023 09:29:06

A navegação consulta e descarregamento dos títulos inseridos nas Bibliotecas Digitais UC Digitalis, UC Pombalina e UC Impactum, pressupõem a aceitação plena e sem reservas dos Termos e Condições de Uso destas Bibliotecas Digitais, disponíveis em https://digitalis.uc.pt/pt-pt/termos.

Conforme exposto nos referidos Termos e Condições de Uso, o descarregamento de títulos de acesso restrito requer uma licença válida de autorização devendo o utilizador aceder ao(s) documento(s) a partir de um endereço de IP da instituição detentora da supramencionada licença.

Ao utilizador é apenas permitido o descarregamento para uso pessoal, pelo que o emprego do(s) título(s) descarregado(s) para outro fim, designadamente comercial, carece de autorização do respetivo autor ou editor da obra.

Na medida em que todas as obras da UC Digitalis se encontram protegidas pelo Código do Direito de Autor e Direitos Conexos e demais legislação aplicável, toda a cópia, parcial ou total, deste documento, nos casos em que é legalmente admitida, deverá conter ou fazer-se acompanhar por este aviso.

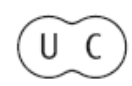




\section{RerCEDöUA}

N. ${ }^{21}$ _Ano XI_1. 08

\section{) Doutrina}

Direitos Humanos, Ambiente e Sustentabilidade

Klaus Bosselmann

O principio da conciliação : fumo a um controlo da "sustentabilidade"?

Chantal Cans

Implementaçäo da Agenda Local 2l em Portugal:

Desafios para a Sustentabilidade Local
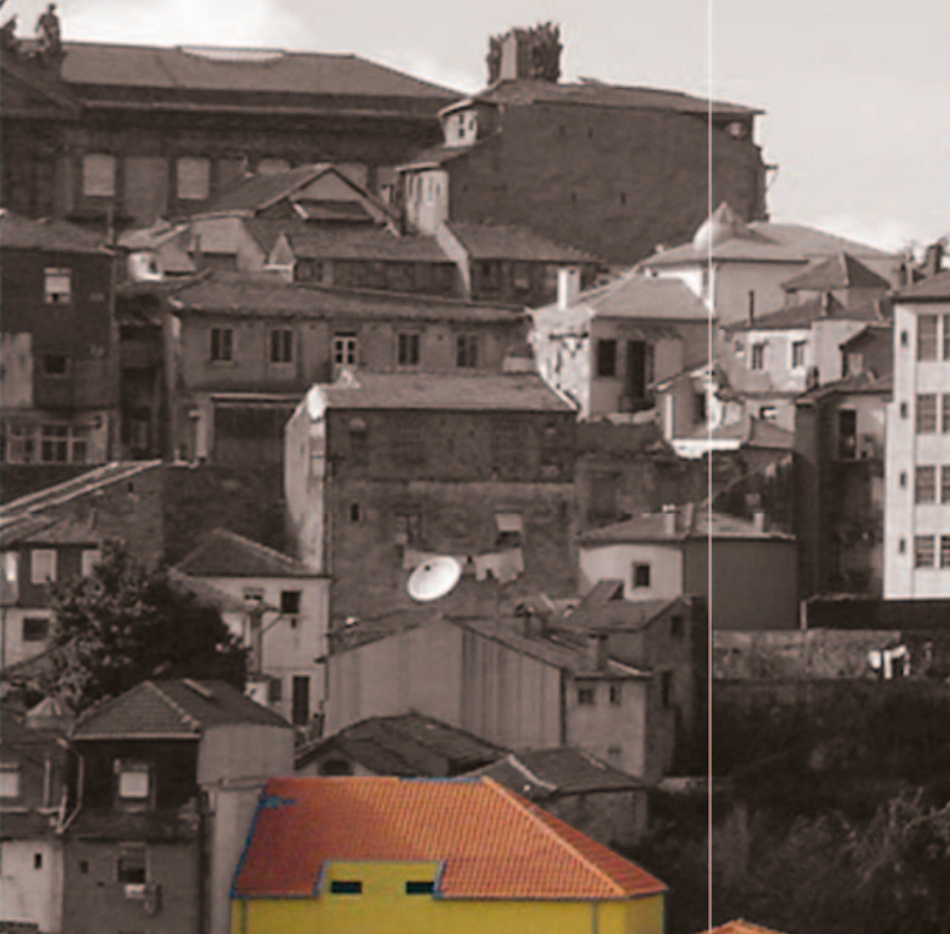

Teresa Fidélis

Sara Moreno Pires

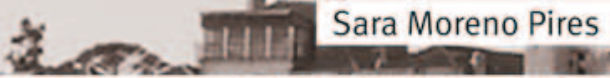

O Regime Jurídico Excepcional da Reabilitiaçäo Urbana [Decreto Lei 104/2004, de 7 de Maio]



Revista do Centro de Estudos de Direito do Ordenamento, do Urbanismo e do Ambiente Urbanism, Territorial Order and Environment Studies Center Law Review 


\section{Directiva Inundações: novas perspectivas}

\section{Comentário}

Na madrugada do dia 27 de Janeiro de 2001, a ruptura de um dique no Baixo Mondego originou danos em várias explorações agro-pecuárias e numa loja de vestuário situados a jusante. A ruptura do dique deu-se na sequência de três inundações consecutivas ocorridas entre Dezembro de 2000 e Janeiro de 2001.

Os particulares afectados reagiram judicialmente contra o INAG junto do TAF de Coimbra, tentando obter o ressarcimento dos danos provocados pela inundação ${ }^{1}$. Apesar de a factualidade ser idêntica, o TAF de Coimbra não se pronunciou uniformemente.

Apresentaremos de seguida duas sentenças contraditórias emitidas pelo TAF de Coimbra. Com efeito, o INAG foi absolvido em três dos quatro casos julgados pelo TAF de Coimbra. Só numa das sentenças o juiz responsabilizou o INAG pelos danos resultantes da ruptura do dique.

O TCAN ainda não se pronunciou relativamente aos recursos interpostos, quer pelos particulares - nos casos de absolvição - quer pelo INAG - no caso de condenação. De facto, ainda existe a possibilidade de uniformizar o tratamento judicial das situações mencionadas.

Finalmente, indagaremos sobre os contributos que a Directiva 2007/60/CE, de 23 de Outubro, relativa à avaliação e gestão dos riscos de inundações (Directiva Inundações), pode trazer para a solução de casos semelhantes no futuro.

\section{Absolvição do INAG}

Um dos casos judiciais diz respeito a uma exploração localizada em Formoselha em que morreram aproximadamente 16 o bovinos. 0 proprietário, Fernando Reis, exigiu ao INAG uma indemnização superior a 198 mil euros. O Autor fundamentou a sua pretensão na negligência do INAG no que respeita à manutenção e conservação do dique da margem esquerda do Baixo Mondego.

O INAG opôs-se a este entendimento afirmando a "excepcionalidade do fenómeno". Sustentou que o projecto de Regularização do Baixo Mondego foi elaborado para suportar cheias com um período de retorno de 100 anos (cheia centenária, isto é, cheia cuja probabilidade é de uma em cada 100 anos). Ora, ficou provado que, no seu conjunto, as cheias de Dezembro de 2000 e Janeiro de 2001 constituíam um evento cujo período de retorno era de 140 anos. E acrescentou ainda que as fragilidades reveladas pelos diques longitudinais em vários pontos resultaram de assentamentos e erosão provocados pelos danos das cheias anteriores.

O tribunal considerou que as circunstâncias do caso concreto eram "absolutamente imprevisíveis ou incontroláveis", e concluiu que não foi a falta de diligência do Réu que causou os danos provocados ao Autor.

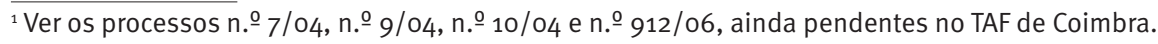




\section{$\operatorname{RerCEDöUA~}$ \\ > Jurisprudência}

Para além disso, o tribunal lembrou que o terreno do Autor se localiza numa "Zona Ameaçada por Cheia” identificada na Carta de Reserva Agrícola Nacional e Reserva Ecológica Nacional.

O TAF de Coimbra decidiu por isso absolver o INAG ${ }^{23}$. Decisão idêntica a esta foi também proferida em dois outros casos: acção proposta pela Agripartes Portuguesa - Acessórios e Máquinas Lda. ${ }^{4}$; e acção proposta pelo Pronto-a-vestir Veneza Lda. ${ }^{5}$.

\section{Condenação do INAG}

Em sentido divergente ao do caso anterior, o TAF de Coimbra condenou o INAG no âmbito do processo $n . \stackrel{0}{7} / 04.5 \mathrm{BECBR}^{6}$.

Neste processo, os Autores ${ }^{7}$ pretendiam ver indemnizados os danos que a cheia de 2001 provocou no estabelecimento agro-pecuário conhecido como Quinta da Giralda. A cheia destruiu construções, culturas, equipamentos, máquinas e a maioria dos animais da quinta. No total, os danos atingiram aproximadamente 450 mil euros (contabilizaram-se os danos emergentes e os lucros cessantes).

Mais uma vez, o INAG procurou eximir-se de responsabilidade invocando a excepcionalidade das cheias (período de retorno superior a cem anos). Referiu também que as edificações dos Autores se encontravam em zonas inundáveis e por isso sujeitas aos efeitos das cheias que ultrapassassem o período de retorno de cem anos. E defendeu ainda a inexistência de nexo de causalidade entre a ruptura do dique e os danos produzidos. Estas alegações não foram acolhidas pelo tribunal. O TAF de Coimbra considerou que "a destruição e desaparecimento dos bens dos autores (...) foi um resultado adequado e normal do facto (colapso do dique)".

Ficou provado neste processo que dois dos três sifões de descarga situados na margem direita do leito central não funcionaram na sua plenitude, não descarregando os volumes de água para que foram projectados.

Além disso, a cidade de Coimbra (Açude) deveria estar protegida contra a cheia milenária (2000 $\mathrm{m}^{3} /$ segundo). Ora, este valor não foi ultrapassado por nenhuma das três cheias ocorridas em Dezembro de 2000 e Janeiro de 2001. Assim, a ruptura do dique só pode ter resultado de uma anomalia na obra.

Acrescente-se ainda que foram elaborados relatórios e pareceres pela Ordem dos Engenheiros (Região Centro) e pelo Departamento de Engenharia Civil. Num desses relatórios pode ler-se que houve ineficiência e deficiente organização do INAG na gestão da obra. 0 INAG foi atacado por "gestão de cheias não adequada", "gestão corrente de diques não adequada" e "gestão de emergência dos diques não adequada". E mais, num dos relatórios afirma-se que "teria bastado que uma só das três gestões referidas tivesse sido adequada para que o desastre se não tivesse verificado".

\footnotetext{
${ }^{2}$ Ver sentença do TAF de Coimbra, de 13 de Fevereiro de 2009, processo n. ${ }^{\circ}$ 912/06.8BECBR.

2 O INAG alegou a ocorrência do efeito "piping", mas não conseguiu provar tal efeito.

${ }^{3}$ Consideramos que houve um aspecto que não foi esclarecido: saber se o INAG poderia ou não ter comunicado o risco de inundação, uma vez que ficou provado que os dados fornecidos pelo SVARH (Sistema de Vigilância e Alerta de Cheias) permitiam prever antecipadamente, em cerca de três horas, a ocorrência da cheia de 27 de Janeiro de 2001, na bacia do Mondego.

${ }^{4}$ Ver sentença do TAF de Coimbra, de 19 de Setembro de 2008, processo n.ำ 9/04.9BECBR.

${ }^{5}$ Ver sentença do TAF de Coimbra, de 29 Setembro de 2008 , processo n. .0 10/04.9BECBR.

${ }^{6}$ Ver sentença do TAF de Coimbra, de 19 de Setembro de 2008, processo n. ${ }^{\circ} 7 / 04.5$ BECBR.

7 Os Autores desta acção são: Maria Amélia Vicente de Carvalho de França Martins, Maria João Vicente de Carvalho de França Martins, José Manuel Rodrigues de Oliveira, e António Miguel Vicente de Carvalho de França Martins.
} 
Houve portanto violação de um dever de cuidado ${ }^{8}$. Não foi cumprido o dever de vigiar as condições de segurança e funcionamento do dique. O INAG actuou portanto de um modo que fica abaixo do exigido e esperado. Não sendo possível determinar a autoria pessoal da omissão ilícita, a culpa será imputada à pessoa colectiva em virtude do funcionamento anormal do serviço9.

Uma vez verificados todos os pressupostos da responsabilidade civil extracontratual do Estado (facto, ilicitude, culpa, nexo de causalidade e dano), o TAF de Coimbra condenou o INAG ao pagamento duma indemnização de aproximadamente 121 mil euros ${ }^{10}$.

\section{Autonomização do regime jurídico relativo à prevenção e mitigação das inundações}

Actualmente, não existe um diploma que estabeleça uma disciplina jurídica autónoma no domínio da prevenção e mitigação dos riscos de inundações.

Todavia, esta situação será em breve alterada por impulso comunitário. Com efeito, em 2007 foi adoptada a Directiva Inundações. Deve assinalar-se que esta é a primeira directiva a incidir sobre a prevenção de riscos naturais, o que só por si indicia a importância dos riscos de inundações ao nível comunitário.

Contudo, esta directiva ainda não foi transposta para o ordenamento jurídico português ${ }^{11}$. Isto significa que os cidadãos ainda não se podem fazer valer do enquadramento jurídico a que a directiva dará origem.

No entanto, já é possível reflectir sobre os contributos que a Directiva Inundações pode trazer para a resolução de casos idênticos àqueles que acima descrevemos.

\subsection{Directiva Inundações: definições e cartografia}

A Directiva Inundações começa por estabelecer as definições de inundação e risco de inundação. Assim, estabelece-se que deve entender-se por inundação toda a "cobertura temporária por água de uma terra normalmente não coberta por água. Inclui as cheias ocasionadas pelos rios, pelas torrentes de montanha e pelos cursos de água efémeros mediterrânicos, e as inundações ocasionadas pelo mar nas zonas costeiras, e pode excluir as inundações com origem em redes de esgotos" (artigo 2.ำ n.ำ 1). 0 risco de inundação, por seu turno, é "a combinação da probabilidade de inundações e das suas potenciais consequências prejudiciais para a saúde humana, o ambiente, o património cultural e as actividades económicas" (artigo 2.ำ n.ำ2).

No entanto, e uma vez que a origem e as condições de surgimento das inundações são muito heterogéneas nos diversos Estados-Membros, a directiva deixa uma ampla margem de manobra aos Estados no que diz respeito ao nível de protecção a exigir e às medidas a adoptar para atingir esse nível de protecção. Deste modo, são os Estados-Membros que fixam os objectivos em matéria de gestão das inundações ${ }^{12}$.

\footnotetext{
${ }^{8}$ O INAG alegou a ocorrência do efeito "piping”, mas não conseguiu provar tal efeito no caso concreto.

${ }^{9}$ Cfr. Acórdão do STA, de 20 de Novembro de 2002, processo n.ํ903/02: “A culpa de uma pessoa colectiva (...) não se esgota na imputação de uma culpa psicológica aos agentes que actuaram em seu nome, pois o facto ilícito gerador dos danos pode resultar de um conjunto, ainda que imperfeitamente definido, de factores próprios da deficiente organização ou falta de controlo, de vigilância ou fiscalização exigíveis em determinadas funções, ou de outras falhas que as reportam ao serviço como um todo".

${ }^{10} \mathrm{~A}$ indemnização concedida foi de apenas 121 mil euros e não de 450 mil euros porque se descontou o montante das ajudas do Estado a que os Autores acederam no âmbito de uma linha de apoio criada para minorar as consequências da cheia de 2001.

${ }^{11} \mathrm{O}$ prazo de transposição da Directiva Inundações é o dia 26 de Novembro de 2009.

${ }^{12}$ Ver artigo $7 . \stackrel{0}{\text { n. }} \stackrel{\circ}{2}$.
} 


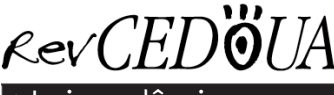

A margem de manobra concedida pela directiva não deve todavia confundir-se com uma total discricionariedade. De facto, a Directiva Inundações fixa uma série de procedimentos que os Estados-Membros terão de executar obrigatoriamente no âmbito da avaliação e gestão do risco de inundação.

Desde logo, a Directiva Inundações começa por impor a realização de uma avaliação preliminar (capítulo II da Directiva Inundações). Trata-se de uma fase em que a análise do risco é um pouco superficial, até porque o prazo para apresentar os resultados é curto.

A avaliação preliminar visa determinar quais as zonas em relação às quais se pode concluir que existem riscos potenciais significativos ou em que a concretização de tais riscos é provável (artigo 5. ${ }^{-}$). Esta avaliação deverá fundar-se em informações disponíveis ou facilmente dedutíveis (artigo 4. ${ }^{\circ}$ n. ${ }^{-}$). Estas informações incluem registos históricos e estudos sobre a evolução do risco de inundação a longo prazo, que devem ter em consideração o impacto das alterações climáticas.

A avaliação preliminar deverá fornecer, no mínimo, cartas da bacia ou sub-bacia hidrográfica; a descrição das inundações ocorridas no passado que tenham tido impactos negativos importantes; a descrição de inundações significativas no passado, sempre que se possam prever consequências prejudiciais significativas resultantes da ocorrência de inundações semelhantes no futuro; e a avaliação das potenciais consequências prejudiciais futuras das inundações (artigo $4 . .^{\circ}$ n. ${ }^{\circ}$ ).

Quando se trata de regiões hidrográficas internacionais, existe o dever de os EstadosMembros garantirem o intercâmbio das informações relevantes entre as autoridades competentes interessadas (artigo 4. $.{ }^{\circ} .{ }^{\circ} 3$ ).

Salienta-se ainda o facto de ser da competência de cada Estado a decisão sobre quais as zonas em que existem riscos significativos ou cuja materialização seja bastante provável. No fundo, após a avaliação preliminar, caberá a cada Estado a decisão sobre quais as zonas sobre as quais incidirão as cartas de zonas inundáveis e de riscos, e os planos de gestão do risco de inundação.

A avaliação preliminar dos riscos de inundações terá de ser concluída até 22 de Dezembro de 2011 (artigo 4.ำ n.ํㅜ) .

Depois da fase da avaliação preliminar, a Directiva Inundações impõe ainda a elaboração de cartas de zonas inundáveis (CZI) e cartas de riscos de inundações (CRI). Estas são um instrumento de informação que fornece a base para fixar prioridades e tomar decisões no âmbito da gestão dos riscos de inundações. Estas cartas permitem mostrar as consequências negativas potenciais para diferentes cenários, e contêm informações sobre as fontes potenciais de poluição ambiental ${ }^{13}$.

As CZI são cartas que cobrem zonas geográficas susceptíveis de serem inundadas (artigo $6 . .-0.0$ 3), e podem ser desenhadas de acordo com três cenários possíveis: probabilidade fraca (cenário de fenómenos extremos); probabilidade média de cheias (periodicidade igual ou superior a 100 anos); e probabilidade elevada ${ }^{14}$. Cada um dos cenários terá de mencionar a amplitude da inundação, a profundidade de água (só nalguns casos), e a velocidade da corrente ou do caudal.


riscos que podem ser desencadeados pelas inundações. Com efeito, as inundações podem gerar outros riscos. Pense-se no caso de uma inundação que atinja uma indústria química. Nesse caso, ao risco de inundação acresce o risco de poluição ambiental.

${ }^{14} \mathrm{~A}$ Directiva Inundações não determina o que deve entender-se por probabilidade elevada. Contudo, tal probabilidade era fixada na proposta de directiva do Parlamento Europeu e do Conselho relativa à avaliação e gestão das inundações [SEC(2006)66] apresentada pela Comissão em 18 de Janeiro de 2006. Assim, considerava-se inundações de probabilidade elevada, aquelas cuja periodicidade provável fosse de uma em cada dez anos.
} 
Apesar de tudo, a Directiva Inundações não determina qual a probabilidade a ter em conta na projecção de um cenário de fenómeno extremo. Caberá por isso aos Estados-Membros fixar qual a probabilidade a atender. Todavia, terão de se considerar obrigatoriamente os cenários que já se tenham produzido no passado, ainda que a sua periodicidade seja inferior à probabilidade fixada pelo Estado-Membro. Assim, em Portugal, deverá cartografar-se a hipótese de ocorrer uma inundação idêntica à que se produziu na sequência do terramoto de 1755 .

Para além das CZI, é ainda necessário elaborar as CRI. As CRI são cartas em que se indicam as consequências da ocorrência das inundações nos cenários previstos nas CZI (artigo 6.ำ..$\stackrel{5}{5}$ ). É nestas cartas que devem constar elementos relativos a pessoas potencialmente afectadas pelas inundações; instalações que possam originar poluição ambiental caso sejam atingidas pelas inundações; tipos de actividade económica nas zonas potencialmente afectada; informação sobre eventuais inundações que possam arrastar elevados volumes de sedimentos e detritos; informações relativas a importantes fontes de poluição; e outras informações que os Estados-Membros considerem úteis.

Os Estados-Membros podem decidir que nas zonas costeiras que já são alvo de uma protecção adequada, e nas zonas em que as inundações se devem a águas subterrâneas, a elaboração das CZI e das CRI se limita às zonas abrangidas nos cenários de eventos extremos.

As zonas em que não existam riscos significativos não devem ser imediatamente excluídas do domínio da gestão do risco de inundação. Pode acontecer que essas áreas de riscos pouco significativos tenham um elevado potencial de protecção contra as inundações.

Tanto as CZI como as CRI deverão estar concluídas até 22 de Dezembro de 2013 (artigo $6 . . \mathrm{n} . .0$ ). 0 prazo é relativamente curto pelo que deverá proceder-se rapidamente à avaliação dos recursos humanos e financeiros disponíveis para atingir os objectivos visados.

\subsection{Directiva Inundações: planeamento}

Com base nas informações contidas nas CZI e nas CRI, deverão de seguida elaborar-se os planos de gestão dos riscos de inundação (PGRI) - capítulo IV da Directiva Inundações. Estes planos deverão ser elaborados nas zonas em que existem riscos potenciais significativos, ou em que a materialização desses riscos pode considerar-se bastante provável.

Cabe a cada Estado-Membro decidir os locais onde considera que o nível de exposição de interesses é tal que convém planear a gestão do risco, assim como o objectivo de gestão do risco.

Os planos deverão conter objectivos apropriados para reduzir as consequências negativas potenciais sobre a saúde humana (inclui-se aqui não apenas a perda de vida humanas mas também o risco de poluição), o ambiente e a actividade económica.

Dada a diversidade das situações existentes na Comunidade, os planos deverão ter em consideração as características próprias da zona, sem deixar de assegurar a coordenação apropriada no seio das bacias hidrográficas.

Apesar da heterogeneidade dos Estados-Membros, os planos de gestão terão de conter: as conclusões da avaliação preliminar dos riscos de inundação; as cartas de zonas inundáveis e as cartas de riscos de inundações e as conclusões que delas podem ser tiradas; a descrição dos objectivos apropriados em matéria de gestão de riscos de inundação definidos; a síntese das medidas que visam atingir os objectivos apropriados em matéria de gestão dos riscos de inundação.

Ora, como decorre do exposto, os planos fixarão com exactidão não só as áreas expostas aos riscos, mas também os níveis de protecção almejados para cada zona. Assim, evitar-se-ão eventuais imprecisões quanto ao nível de protecção que deverá garantido pelas estruturas hidráulicas. 


\section{$\operatorname{RerCEDőUA~}$}

\subsection{A informação e participação do público}

A Directiva Inundações impõe também a obrigação de os Estados-Membros porem directamente à disposição do público os resultados da avaliação preliminar, as CZI, as CRI e os PGRI. Esta obrigação resulta do artigo 10. n. 1 que consagra desta forma o direito de informação em matéria de risco de inundação.

Por outro lado, prevê-se ainda a obrigação de promover a participação dos cidadãos na elaboração dos PGRI no artigo 10.ำ n.ำ 2: "Os Estados-Membros devem encorajar a participação activa dos interessados na elaboração, no reexame e na actualização dos planos de gestão dos riscos de inundações".

Estas obrigações revestem grande importância por várias ordens de razões. Primeiro, permite-se que os cidadãos tomem conhecimento dos riscos e adoptem, por sua própria iniciativa, medidas de auto protecção. Em segundo lugar, aumenta-se a aceitação pública das medidas tomadas pelos Estados ${ }^{15}$. Com efeito, a imposição de proibições ou condicionamentos à edificação, por exemplo, é mal aceite tanto pelos cidadãos, como pelos próprios detentores do poder ao nível local, quando não existe uma percepção clara dos riscos. O risco é pura e simplesmente ignorado ou negado, condenando à partida todo o tipo de políticas de prevenção de riscos.

Nos casos que acima descrevemos, a informação e participação do público contribuiriam para consciencializar os Autores para os riscos que correm. Na verdade, não existem estruturas de protecção infalíveis. É portanto necessário preparar as pessoas para a possibilidade de ruptura das estruturas de protecção, designadamente com a realização de seguros que cubram os riscos de eventos com um período de retorno superior ao previsto na projecção das estruturas de protecção. Para além disso, a consciencialização dos cidadãos contribui também para o abandono de comportamentos de auto-exposição aos riscos, designadamente a realização de construções em zonas expostas aos riscos de inundações. Com efeito, a auto-exposição ao risco é em muitos casos o resultado da ignorância relativamente a esta mesma exposição.

\section{Directiva Inundações: novo rumo}

Apesar de ainda não termos conhecimento das decisões do TCAN, a realização de juízos contraditórios tendo por base uma factualidade idêntica (ruptura de um dique) acaba por contribuir para o descrédito da justiça. O INAG foi simultaneamente condenado e absolvido pelos mesmos factos.

Os juízos contraditórios resultaram da dificuldade na obtenção de dados relativos aos níveis de protecção para os quais as estruturas hidráulicas foram projectadas. Na verdade, a entidade com acesso privilegiado a estes dados é exactamente aquela que se procura responsabilizar: o INAG. Por isso, é necessário criar instrumentos que facilitem o acesso a documentos desta natureza.

Neste sentido, consideramos que a transposição da Directiva Inundações terá uma importância significativa. Desde logo, será criado um regime jurídico específico e autónomo para a prevenção das inundações. Em segundo lugar, permitirá não só a determinação do grau de exposição aos riscos de inundações como também a fixação do nível de protecção adequado para cada zona exposta a estes mesmos riscos.

${ }_{15}$ Cfr. THIERRY TANQUEREL, La Participation de la Population à l'Aménagement du Territoire, Payot Lausanne, 1988, p.70 : "Grâce à la force de l'idéologie démocratique ou parce que l'habitant sait, ou croit, que son avis a été examiné dans le processus de décision, la participation de la population exerce un effet de légitimation". 
Desta forma, nos casos em que ocorram danos provocados por inundações, será mais fácil determinar qual a medida da responsabilidade do Estado, visto que os PGRI terão de prever obrigatoriamente os objectivos de protecção para a respectiva circunscrição.

Em contrapartida, os cidadãos passarão a ter mais responsabilidades no caso de se instalarem ilegalmente em zonas expostas aos riscos, uma vez que passarão ter ao seu dispor a informação relativamente aos riscos a que estão expostos.

Em síntese, a transposição da Directiva Inundações, ao identificar claramente as zonas expostas e os níveis de protecção exigiveis, acaba por transformar-se numa espada de dois gumes para os cidadãos que procuram responsabilizar o Estado: se é verdade que os juízes terão mais facilidade em encontrar o nível de protecção exigível, também não é mentira que as edificações ilegais serão mais facilmente identificadas.

Finalmente, deve recordar-se que o facto de existir uma directiva relativa à avaliação e gestão dos riscos de inundações significa que, em última instância, será sempre possível activar a responsabilizar o Estado junto do Tribunal de Justiça das Comunidades Europeias. E se estiverem em causa direitos previstos na Convenção Europeia dos Direitos do Homem, será ainda possível recorrer à protecção do Tribunal Europeu dos Direitos do Homem.

Márcio Albuquerque Nobre Investigador do CEDOUA

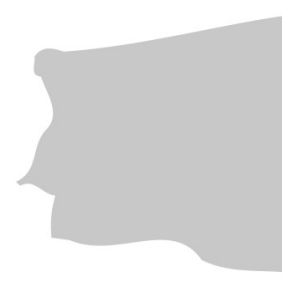

